\title{
Does monetary punishment crowd out pro-social motivation? A natural experiment on hospital length of stay*
}

Tor Helge Holmås† Egil Kjerstad† Hilde Lurås Odd Rune Straumeq

\begin{abstract}
We study whether the use of monetary incentives might be counter-productive. In particular, we analyse the effect of fining owners of long-term care institutions who prolong length of stay at hospitals. Exploiting a unique natural experiment involving changes in the catchment areas of two large Norwegian hospitals, we find that hospital length of stay are longer in the hospital using fines to reduce length of stay compared with the hospital not using monetary punishment. We interpret these results as examples of monetary incentives crowding-out agents' intrinsic motivation, leading to a reduction in effort.
\end{abstract}

Keywords: Motivation crowding; Intrinsic motivation; Monetary punishment; Hospital length of stay.

JEL Classification: D64; I18; Z13

\footnotetext{
* We thank Karl Ove Aarbu and participants at the 9th European Health Economic s Workshop (Bergen, 2008) for valuable comments.

$\dagger$ Health Economics Bergen (HE B), University of Bergen, Fosswinckelsgate 14, 5007 Bergen, Norway. E -mail tor.holmas@econ.uib.no

† Institute for Research in Economics and Business Administration (SNF), Breiviksveien 40, 5045 Bergen, Norway; and Health Economics Berge n (HEB), Norway. E-mail: egil.kjerstad@snf.no

$\S$ Helse Øst Health Services Research Centre, Akershus University Hospital, Norway. E-mail: hilde.luras@ahus.no C Corresponding author. Department of Economics and NIPE, University of Minho, Campus de Gualtar, 4710-057 Braga, Portugal; and Health Economics Bergen, Norway. E-mail: o.r.straume@eeg.uminho.pt.
} 


\section{Introduction}

Are explicit monetary incentive schemes necessarily the best way to motivate economic agents to perform in accordance with social objectives? We discuss the issue based on an empirical study of the behaviour of health care and long-term care providers in Norway. Our point of departure is principal-agent theory. Much theoretical research has been devoted to how conflicting interest between a principal and an agent can optimally be aligned. In cases of symmetric information, the alignment is based on instructions. In the more interesting cases where the relationship can be described as one of asymmetric information, the optimal reward scheme involves monetary incentives. The principal designs a revelation mechanism altering the relative prices such that the agent, depending on its type, chooses the optimal level of effort. This revelation comes at a cost, i.e., the agent receives an information rent. In the case of regulation, much of the same logic applies. The regulator (social planner) designs an incentive scheme that makes the regulated firm perform in the best interest of society.

In recent years, principal-agent theory has been challenged both theoretically and empirically on the grounds that information rent is potentially not the only cost component. The theory of motivation crowding stresses the link between extrinsic and intrinsic motivation (see Frey, 1997, for a comprehensive treatment). In particular, the theory stipulates that some forms of external interventions - for example, the use of explicit monetary incentives - might undermine the agent's intrinsic motivation to perform a particular task and have unintentional adverse effects in the form of lower effort. The presence of such crowding effects for the case of external monetary rewards has long been recognised in the field of cognitive psychology, where the effect has been termed 'The Hidden Cost of Reward' (see, e.g., Lepper and Greene, 1978). For the purpose of economics, this effect has later been generalised (Frey, 1997) to potentially emanate from all kinds of external interventions and regulations, be they positive (rewards) or negative (punishment).

In order to incorporate the concept of intrinsic motivation into economic thinking and modelling, there are at least two approaches one could take. In the Motivation Crowding Theory as proposed by Frey (1997), a change in intrinsic motivation - resulting from some external 
intervention - is attributed to a change in preferences. ${ }^{1}$ Bénabou and Tirole $(2003,2006)$, on the other hand, maintain the standard economics assumption of fixed preferences and attribute a change in intrinsic motivation to a change in the agent's perception of the performed task or the perception of himself. In the latter approach, the signalling effect of different types of external intervention on the agent's information plays a crucial role in explaining the link between extrinsic and intrinsic motivation.

The survey by Frey and Jegens (2001) shows that not only is the motivation crowding effect a theoretical possibility, but also an effect of empirical relevance. In addition to an abundance of experimental evidence, especially in psychology, but also to an increasing extent in economics, there are several econometric studies identifying motivation crowding effects, including Barkema (1995), Frey and Oberholzer-Gee (1997) and Gneezy and Rustichini (2000). The quite famous study by Gneezy and Rustichini can serve as an illustrative example. They studied the effect of introducing a fine for parents who came too late to collect their children at a day-care centre in Israel. This led, paradoxically, to a substantial increase in the number of latecoming parents, something that cannot be explained by standard economic incentive theory. However, such an outcome would be consistent with a motivation crowding story: the introduction of monetary fines undermined the parents' intrinsic motivation for collecting their children on time.

Our study is also an empirical investigation of how punishment may adversely affect effort. In particular, we study the effects of fining owners of long-term care institutions who prolong hospital length of stay (LOS), driving hospital costs upwards and causing bed-blocking. How should the interaction between hospitals and primary care be regulated in order to achieve shorter LOS and better overall care for the elderly? Should the Ministry of Health rely on letting the hospitals use monetary punishment of the municipalities that are not able to provide long-term care in time? Or by relying on implicit incentives stimulating the agents to coordinate their efforts?

By exploiting changes in the catchment areas of two large hospitals located in the metropol-

\footnotetext{
${ }^{1}$ Lai et al. (2003) follow this approach in a theoretical study of environmental regulations and social norms, where firms' intrinsic motivation for complying with environmental norms is affected by extrinsically imposed regulation (pollution taxes). The motivation crowding effects of price-incentive based policies in environmental management is also discussed by Frey (1993).
} 
itan area of the capital of Norway (Oslo), we can study whether long-term care institutions respond to changes in the way their interaction with hospitals are regulated. Henceforth, we have a natural experiment in which we can study the effects on LOS of patients belonging to municipalities that first were faced with punishment from one of the hospitals and subsequently invited to a closer cooperation, without economic punishment, with the new hospital, i.e., changes from punishment to dialogue and vice versa

Our results support previous studies that incentives schemes or regulatory efforts based on monetary punishment may lead to sub-optimal allocation of resources compared to regimes not relying on monetary incentives. In particular, we find that LOS changes as result of the change in extrinsic motivation (or contingent rewards, here punishment through fines vs nonpunishment) that the long-term care providers are faced with. Both LOS and bed-blocking are reduced for patients belonging to municipalities that are transferred from a hospital relying on the punishment strategy to a hospital relying on cooperation, and LOS and bed-blocking are increased for patients belonging to municipalities that are transferred the other way around.

The paper is organized as follows: In Section 2 the institutional setting is discussed in some detail. Section 3 presents a theoretical framework in the context of motivation crowding. Data and descriptive statistics are given in Section 4, while Section 5 presents the econometric method. Results are reported in Section 6, while Section 7 closes the paper with some discussion and concluding remarks.

\section{Institutional background}

The Norwegian government has for years been concerned with long hospital length of stay (LOS) in general and bed-blocking by elderly patients in particular. The responsibility for elderly patients is divided between state owned hospitals ${ }^{2}$, which are responsible for specialist

\footnotetext{
${ }^{2}$ From 1 July 1997 activity based financing (ABF) was introduced in the hospital sector. Initially $30 \%$ of the expected cost was paid according to activity (the number of patients treated and the patients' DRGs) while 70 $\%$ came from a block grant. In 2002 and 2003 the activity-based component was increased to, respectively, 55 and $60 \%$, while the component was reduced back to $30 \%$ in 2005. In 2005 the daily average operation cost in Norwegian hospitals amounts to 7-8.000 NOK (SAMDATA).
} 
care, and patients' home municipalities ${ }^{3}$, having the responsibility for long-term care. By this division of responsibility, municipalities and hospitals have conflicting interests regarding length of stay, which is an important cost component for either of the parties.

When an old, frail patient leaves the hospital after medical treatment the responsibility is carried over from the hospital to the patient's home municipality, a transfer which require coordination and cooperation between two governmental levels. One regulatory policy to facilitate a smooth transfer has been that all hospitals and all municipalities are expected to have a coordinating unit for transfers between hospitals and long term care services (HOD 2001). The coordinating unit at the hospital is supposed to contact the coordinating unit in the municipality when a patient' discharge date and need for care is clarified. The coordinating unit in the municipality, on the other hand, will decide when to admit the patient and is responsible for allocating the necessary care resources (nursing home, home nursing, etc.) to the patient.

Another regulatory effort to initiate an early transfer has been to allow hospitals to impose penalty payment to municipalities that cannot provide care services in time (HOD 1998). This administrative regulation is designed such that the hospital can require a daily payment if the patient still stays in hospital ten days (seven in Oslo) after the medical treatment is completed; i.e., ten (seven) days after the hospital has put up a discharge date for the patient. The daily penalty rate amounts to $1.600 \mathrm{NOK}\left(2.000 \mathrm{NOK}\right.$ in Oslo). ${ }^{4}$ However, not all hospitals make use of the administrative regulation that allows them to punish the municipalities economically. In fact, we have a natural experiment taking place in two Norwegian hospitals where one of the hospitals make us of penalty payment, while the other hospital do not use this possibility. Instead the hospital - in cooperation with the municipalities in the catchment area - has worked out a contractual obligation that is based on dialogue between the two parties and in detail regulates the discharge process. In the following we call the first hospital the 'payment hospital' (P), while the other is called the 'dialogue hospital' (D). ${ }^{5}$ In April 2004 parts of Hospital P's catchment

\footnotetext{
${ }^{3}$ The organisation of primary health care and caring services (both nursing homes and home care) in Norway is the responsibility of the municipalities, which is the lowest governmental level. The municipalities are responsible for the finance of caring services, and nursing homes are financed through a yearly block grant. Primary health care is partly financed by the municipalities and partly by the state (via the national insurance company).

${ }^{4}$ There are no national registrations on average daily operation costs in Norwegian nursing homes, but it seems that an honest estimate is between 1.500 and 1.700 NOK (personal communication).

${ }^{5}$ We use the terms 'payment hospital' and 'dialogue hospital' to distinguish the two different regimes. However,
} 
area were transferred to D, while parts of Hospital D's catchment area were transferred to P. Comparing length of stay for patients residing in these different areas before and after the structural change, this natural experiment makes the basis of the current analysis.

\section{A motivation crowding theory framework}

As mentioned in the Introduction, the basic idea that monetary incentives may crowd out intrinsic motivation has a strong grounding in psychology, with literature dating back to the early 1970s. ${ }^{6}$ In particular, the relationship between extrinsic and intrinsic motivation has been understood to work through two different psychological processes (see, e.g., Frey and Degen, 2001):

(i) Increased extrinsic control may lead to reduced self-determination. When a higher degree of extrinsic control is imposed on an agent, the agent may feel less responsible and perceives his original intrinsic motivation to be overjustified. Thus, the agent may substitute intrinsic motivation for extrinsic control.

(ii) Increased extrinsic control may lead to reduced self-esteem. Depending on the nature of the extrinsic control, the agent may perceive outside intervention as an effective rejection of his intrinsic motivation. As a result, the agent may reduce his effort.

It is worth mentioning that the motivation crowding theory also opens up for the possibility that extrinsic control crowds in intrinsic motivation. In general, external interventions are expected to crowd out intrinsic motivation if the interventions are perceived to be controlling, but crowd in intrinsic motivation if they are perceived to be supportive (Frey and Degen, 2001). Furthermore, the likelihood of a crowding out effect is also determined by the cognitive conditions characterising the principal-agent relationship. For example, crowding out is more likely if a punishment or reward is perceived as a lack of recognition, where the agent feels that the principal mistrusts or undervalues the agent's intrinsic motivation. Crowding out is also more

it is important to emphasise that the 'payment hospital' is of course free to use cooperation and dialogue in addition to a penalty payment, in order to ease transfer of patients from the hospital to the long-term care institutions. Thus, the important distinction is really between using economic punishment (penalty payment) or not.

${ }^{6}$ Early key references in the field of cognitive psychology are Deci (1971, 1972). See also, e.g., Frey (1993) and Frey and Degen (2001) for discussion and overview of the key literature. 
likely to occur if the punishment or reward is perceived by the agent to be unfair, or even immoral (see, e.g., Frey, 2001, for more discussion).

In the context of the present study, it is reasonable to assume that the 'punishment' scheme, with monetary fines for hospital bed-blocking, would be perceived as a controlling intervention, with an expected crowding-out effect on intrinsic motivation. We can illustrate the postulated link between extrinsic and intrinsic motivation in a simple, stylised model of hospital bedblocking. Consider an elderly patient who - after having undergone hospital treatment - is ready to be discharged from hospital $H$ at time 0 . However, the patient can only be discharged once the long-term care provider $L$ accepts to admit the patient. Let the date of patient transfer from $H$ to $L$ be given by $\tau \geq 0$. The expected total time of care is given by $\bar{t} \geq \tau \geq 0$. Notice that $\tau>0$ implies bed-blocking. We assume that the objective function of $L$ is given by

$$
\Omega=r[\bar{t}-\tau]-C_{L}(\bar{t}-\tau)-p \tau+\alpha\left[U_{H}(\tau)+U_{L}(\bar{t}-\tau)\right]-\beta(p)\left[C_{H}(\tau)-p \tau\right]
$$

where $r$ is the daily fee (paid by the patient and/or third-party payers) for long-term care; $C_{H}(\cdot)$ is the cost of long-term care as a function of the length of stay; $U_{L}(\cdot)$ and $U_{H}(\cdot)$ are patient utility of, respectively, long-term care and hospital stay post-treatment, as functions of the length of stay; $p$ is the daily fine for bed-blocking, issued by $H$; and $C_{H}(\cdot)$ is the cost of hospital care after the patient is ready to be discharged, which includes both the direct cost of hospital stay post-treatment and the indirect cost of postponed treatment for patients on the hospital waiting list. We assume that $C_{i}^{\prime}(\cdot)>0, C_{i}^{\prime \prime}(\cdot) \geq 0, U_{i}^{\prime}(\cdot)>0$ and $U_{i}^{\prime \prime}(\cdot)<0$, where $i=L, H$.

The objectives of $L$ that go beyond pure economic profits, are reflected by the parameters $\alpha$ and $\beta$. In line with the quite standard assumptions of partially altruistic health care providers, we assume that patient utility is partially included in the objective function of $L$, with the degree of altruism measured by $\alpha \in(0,1)$. In addition, the parameter $\beta \in(0,1)$ reflects the extent to which $L$ takes into account the hospital costs of bed-blocking when deciding when to admit the patient for long-term care. Thus, we interpret $\beta$ as the degree of intrinsic motivation of the management/owners of $L$ to contribute to a social good by limiting the extent of hospital bed- 
blocking. The insight from the motivation crowding theory, as discussed above, is incorporated into the model in a reduced-form manner by letting $\beta$ be a function of the extrinsic incentive parameter $p$, where $\beta^{\prime}(p)<0$, implying that extrinsic, monetary incentives crowd out intrinsic motivation.

The extent of hospital bed-blocking is determined by the choice of $\tau$ that maximises $\Omega$. The first-order condition can be expressed as ${ }^{7}$

$$
C_{L}^{\prime}=r+p+\alpha\left(U_{L}^{\prime}-U_{H}^{\prime}\right)+\beta\left(C_{H}^{\prime}-p\right)
$$

The left-hand side of (2) is the marginal profit gain of increasing bed-blocking, consisting of reduced care costs. The right-hand side is the marginal cost of increasing bed-blocking, consisting of four different terms. The first term is the foregone payment for the patient whose admittance is prolonged; the second term is the extra payment to the hospital due to the daily fine; the third term is the net patient utility loss of having to stay longer in hospital before being admitted to the long-term care institution, ${ }^{8}$ weighted by the parameter $\alpha$; finally, the fourth term is the marginal hospital cost of bed-blocking net of the fine (i.e., the part of the costs that are not paid for by $L)$, weighted by the parameter $\beta$.

What is the effect of imposing an economic punishment scheme on the long-term care institution, in order to reduce hospital bed-blocking? We can illustrate the trade-off between extrinsic and intrinsic motivation by considering the effect of a marginal increase in $p$ on $L$ 's optimal choice of admittance date, $\tau^{*}$. Totally differentiating (2), the marginal effect of an increase in the daily fine on bed-blocking is given by

$$
\frac{\partial \tau^{*}}{\partial p}=\frac{(1-\beta)+\beta^{\prime}(p)\left[C_{H}^{\prime}-p\right]}{\partial^{2} \Omega / \partial \tau^{2}}
$$

It is naturally difficult to make clear-cut predictions for the empirical analysis, since the sign of $\partial \tau^{*} / \partial p$ depends on the strength of a postulated crowding effect - given by $\beta^{\prime}(p)$ - that is not

\footnotetext{
${ }^{7}$ Our assumptions on $C_{i}(\cdot)$ and $U_{i}(\cdot)$ ensure that $\Omega$ is concave in $\tau$, guaranteeing that the second-order condition is satisfied.

${ }^{8}$ It is likely that patient utility is higher when staying in the long-term care institution than at the hospital, since the former specialises in the care of elderly patients.
} 
directly observable. However, we can use this simple model for two inter-related purposes; (i) to identify some necessary conditions, based on observable variables, that need to be satisfied in order for a counter-productive effect of economic punishment (i.e., $\partial \tau^{*} / \partial p>0$ ) to be a possibility, and (ii) to identify under which circumstances a counter-productive effect is more likely to occur.

Regarding (i), there are two necessary conditions that must be met. First, in an interior solution, the sign of $\partial \tau^{*} / \partial p$ is ambiguous only if $p<C_{H}^{\prime}$. In other words, a counter-productive effect of imposing a daily fine on bed-blocking is a possibility only if the fine does not fully cover the costs of bed-blocking. Second, and given that $p<C_{H}^{\prime}$, in order to have an interior solution with bed-blocking, i.e., $\tau^{*}>0$, we see from (2) that the marginal cost of long-term care, $C_{L}^{\prime}$, must generally be higher than the daily fine, $p .^{9}$

Regarding (ii), given that the above two necessary conditions are satisfied, we can use (3) to derive the following condition for a positive relationship between $p$ and $\tau^{*}$ :

$$
\frac{\partial \tau^{*}}{\partial p}>0 \text { if }\left|\beta^{\prime}(p)\right|>\frac{1-\beta}{C_{H}^{\prime}-p}
$$

Obviously, the motivation crowding effect, measured by $\beta^{\prime}(p)$, must be sufficiently strong in order for economic punishment, measured by $p$, to have a counter-productive effect. Furthermore, for a given magnitude of the crowding effect, we see that stronger economic incentives are more likely to have a counter-productive effect if the intrinsic motivation $(\beta)$ is higher to begin with, and if the extrinsic motivation $(p)$ is lower to begin with. While the degree of intrinsic motivation, measured by $\beta$, is not directly observable, the degree of extrinsic motivation is. Here it is worthwhile to notice that, while we have modelled a linear fine $p$, the 'punishment regime' in our experiment, as discussed in the previous section, corresponds to a non-linear fine, where the $p=0$ for $\tau<\widehat{\tau}$ (where $\widehat{\tau}=7$ in Oslo and $\widehat{\tau}=10$ in the other catchment areas) and $p>0$ for $\tau \geq \widehat{\tau}$. Thus, in order to apply our theoretical model to the experiment, we have to consider two cases separately:

\footnotetext{
${ }^{9}$ The only exeption is the (unrealistic) case where there is a net utility gain for patients of staying longer in hospital, and the term $\alpha\left(U_{L}^{\prime}-U_{H}^{\prime}\right)<0$ is sufficiently large in absolute value to dominate other effects.
} 
1. If the solution to (2) is given by $\tau^{*} \geq \widehat{\tau}$, the trade-off between extrinsic versus intrinsic motivation is given by (4), and the above discussion of the relative strengths of the different effects applies.

2. If the solution to $(2)$ is given by $0<\tau^{*}<\widehat{\tau}$, we can derive a clear-cut prediction about the effect of introducing a payment scheme, depending on one fundamental assumption:

(a) If introducing a payment scheme crowds out intrinsic motivation only for strictly positive values of $p$, such a scheme has no effect on bed-blocking if $0<\tau^{*}<\widehat{\tau}$.

(b) If introducing a payment scheme crowds out intrinsic motivation also for $p=0$, such a scheme will unambiguously increase bed-blocking if $0<\tau^{*}<\widehat{\tau}$. The interpretation here is that it is the implementation of a payment scheme in itself, and not the actual size of the daily fine, that crowds out intrinsic motivation. Technically, we can represent this case by assuming that $\beta:=\beta_{0}$ in the absence of a payment scheme, and $\beta:=\beta_{P}(p)$ in the presence of such a scheme, with $\beta_{P}(p)<\beta_{0}$ for all $p \geq 0$. It follows from (2) that $\tau^{*}\left(\beta_{P}\right)>\tau^{*}\left(\beta_{0}\right)$ for $p=0$.

\section{Data and descriptive statistics}

In the empirical part of this paper we study hospital length of stay (LOS) for elderly patients. The patient data are taken from the Norwegian Patient Register (NPR) for the years 2002 to 2005. For each patient we have information on length of stay (LOS), age, gender, DRG-weight, diagnoses, number of co-morbidities, whether or not the admission was planned, whether or not the patient is discharged to an institution, the patient's home municipality, etc. We focus on two university hospitals, the first (Hospital P) located in Oslo and the second (Hospital D) located in Akershus, a neighbouring county to Oslo. Table 1 shows average length of stay for patients hospitalized at the two hospitals in 2002 to 2005. From the table we see that LOS for patients younger than 40 was almost the same at the two hospitals, but that LOS for elderly patients, especially patients older than 67, was considerably longer at Hospital P. A possible explanation for these striking differences is that the hospitals have chosen different strategies for 
coping with bed-blocking. Hospital $\mathrm{P}$ has, based on options made available by the Norwegian Ministry of Health, decided to fine the city districts/municipalities that cannot supply long-term care in time for their elderly patients. Hospital D's strategy is to develop ways of coordinating the discharge process with the patient's home municipality and by using resources bolstering cooperation between the hospital and the municipalities the hospital serves.

We have no direct information on whether or not a patient is in need for care after hospitalization, and we therefore restrict our sample to individuals older than 67 who are discharged from hospital to a long-term care institution. For these patients, it is quite clear that the hospital LOS is directly influenced by the municipalities (long-term care providers) since they cannot be discharged from hospital before an institution accepts to admit them. We further restrict our sample to include planned admissions since planned admissions for elderly patients to a large extent follow the catchment areas of the hospitals.

Our contribution is based on what can be termed a natural experiment. Before 2004, the catchment area of Hospital $\mathrm{P}$ consisted of city districts in Oslo, while the catchment area of Hospital D consisted of municipalities in the neighbouring county. In April 2004, two city districts in Oslo were transferred to the catchment area of Hospital D, while, at the same time, three municipalities were transferred to the catchment area of the hospital located in Oslo (Hospital P). In Table 2 we see that before the reform (in 2002 and 2003) very few patients were admitted to the hospital outside the original catchment areas. In 2005, however, 440 patients originally belonging to Hospital D's catchment area were treated at Hospital P, while 471 patients that previously belonged to Hospital P's catchment area were treated at Hospital D. Our main interest in this paper is how the coordinating units in municipalities/city districts that were faced with a new regime towards bed-blocking reacted on this change, compared to coordinating units in other municipalities/city districts in the hospitals' catchment areas. To analyse this issue, we focus on LOS for four groups of patients discharged from a hospital to an institution. The first group consists of patients living in the two city districts that were transferred from Hospital P to Hospital D (P-D), the second group is the patients living in city districts belonging to Hospital $\mathrm{P}$ for the entire period $(\mathrm{P})$, the third group is the patients living 
in the municipalities transferred from Hospital D to Hospital P (D-P), while the fourth group consists of patients living in municipalities belonging to Hospital D for the entire period (D).

Table 3 gives descriptive statistics for the four different groups of patients identified above. We first notice that the patients are quite similar on observable variables like age, gender, DRGweight, etc ${ }^{10}$. However, the most interesting information in Table 3 is the differences in LOS between the patients belonging to groups $\mathrm{P}-\mathrm{D}$ and $\mathrm{P}$, and groups $\mathrm{D}-\mathrm{P}$ and $\mathrm{D}$, respectively. From column one and two in the table, we see that patients from Hospital P's original catchment area on average had 2.59 days longer LOS if they are treated at Hospital $\mathrm{P}$ compared to patients treated at Hospital D. However, for patients living in the original catchment area of Hospital $\mathrm{D}$, we find that patients treated at Hospital P had almost the same LOS as patients treated at Hospital D. For patients from Hospital D's original catchment area, we are able to calculate average LOS for different groups of municipalities over time. ${ }^{11}$ In Table 4, we report LOS over time for the three municipalities transferred from Hospital D to Hospital P, compared with LOS for the municipalities that belonged to Hospital D for the whole period. Patients in the D-P group had an increase in average LOS of around 2.5 days in the period from 2002/2003 to 2005 . Patients living in the municipalities that had Hospital D as their hospital for the entire period, had quite stable LOS, but these LOS were much longer compared with LOS for patients from the municipalities that changed catchment area. This explains why we do not see any differences in LOS between the D-P and the D groups in Table 3.

\section{Econometric model}

The descriptive statistics presented in Section 4 suggest that the coordinating units in municipalities/city districts respond to monetary incentives towards bed-blocking in a counter-productive way. Long-term care providers seem to increase hospital LOS in a regime with monetary fines for bed-blocking, and to reduce hospital LOS when the 'punishment regime' is removed. In this section we outline an econometric framework to identify the effects of the incentive scheme

\footnotetext{
${ }^{10}$ The variable 'Home to institution' is 1 for patients admitted from home and discharged to an institution after hospitalization

${ }^{11}$ Unfortunately, due to a reform reducing the number of districts from 25 to 15 in 2004, this is not possible for the city districts in Oslo.
} 
towards bed-blocking more carefully. Our main estimation strategy is to utilize the change of catchment areas between the hospitals we study. Ideally, in order to capture the effects of changing catchment areas, we would like to know what the LOS would have been if the patients were treated at the hospital in the original catchment area. Since we only observe LOS for these patients with the imposed reform, we let LOS for patients that did not change catchment areas represent the counterfactual. Having panel data from 2002-2005, we are able to compare inter-temporal variation in LOS before and after the imposition of the reform. Therefore, identification relies not only on a before-after comparison, but also on comparison of LOS for patients changing hospital subject to the change in catchment areas with LOS for patients not affected to the reform. Further, following the convention from the treatment literature, we not only have individuals going from an 'untreated' state to a 'treated' state, but also individuals that go from a 'treated' to an 'untreated' state.

In the estimations we employ the following difference-in-differences model:

$$
L O S=\alpha+X_{i t} \beta_{1}+Z_{m t} \beta_{2}+\gamma_{1} D_{P_{-} D}+\gamma_{2} D_{D_{-} P}+a_{m}+\delta_{t}+\varepsilon_{i m t} .
$$

Here, $X_{i t}$ contains time variant observable individual patient characteristics controlling for casemix, $Z_{m t}$ contains time variant observable municipal characteristics, $a_{m}$ is a municipality fixed effect $^{12}, \delta_{t}$ is a time specific effect and $\varepsilon_{i m t}$ is the usual error term. $D_{P_{-} D}$ is a variable that equals 1 for patients living in Oslo but treated at the hospital located in the neighbouring county, while $D_{D_{-} P}$ is a variable that equals 1 for patients living in the neighbouring county, but treated at the hospital located in Oslo. Therefore, the two dummy variables $D_{P_{-} D}$ and $D_{D_{-} P}$ should capture the effect on hospital LOS of the change in catchment areas.

\section{Estimation results}

Based on the discussion and analysis in Section 3, we would expect longer LOS and bed-blocking at the 'payment hospital' compared with the other hospital if motivation crowding is the dom-

\footnotetext{
${ }^{12}$ Oslo is treated as one administrative unit.
} 
inant effect of the punishment scheme. The results from the difference-in-differences models reported in Table 5 seem to confirm this. In the table we report results from two different regressions. In the regression reported in column one, the dependent variable is the total length of stay. For a small subsample of patients ${ }^{13}$ we also know the ready-for-discharge date, and in column two we present results where the dependent variable is length of stay above this date. The last variable is interesting, since it is a direct measure of bed-blocking which should be unaffected by how efficient the hospitals are in treating their patients.

Commenting first on variables describing patient individual characteristics, notice that the coefficient of the age variable (Age) is negative and significant. At first glance, this result might seem unexpected. One reason behind the result could be that older patients are more likely to be transferred earlier from a hospital to another institution to receive care, terminal or otherwise, compared to younger patients with the same illness. Furthermore, men (Male) stay longer at hospital compared to women, but the gender effect is small. As expected, we find that higher DRG weight implies longer LOS. An increase in the DRG weight of one point increases LOS with approximately 1.60 days. Number of co-morbidities is also significant and an additional co-morbidity increases LOS with approximately 1.84 days. We notice that there are significant differences in LOS between the diagnoses. Patients given the diagnosis malignant neoplasm stay on average over four days longer at hospital compared to the benchmark group that consist of all other diagnosis except Diseases in the circulatory system and Diseases in the respiratory system, which stay approximately three and two days longer, respectively. We find it interesting that patients admitted to hospital from their home and discharged to an institution (Home to institution) stay longer at hospital (1.8 days) compared to patients that are admitted to hospital from an institution. An explanation is that these patients constitute an increased care demand for the long-term care providers and that the results follow from supply side limitations.

Having controlled for patient individual characteristics and case-mix, the explanatory variables that capture the effects of the two different incentive systems - From $P$ to $D$ and From $D$ to $P$ - are both significant. Recall from Section 4 that these variables measure the effect on LOS for patients belonging to municipalities that change hospital compared to patients who

\footnotetext{
${ }^{13}$ For descriptive statistics for this sample, see Table 7 in the Appendix.
} 
come from municipalities that does not change hospital. The estimation results are interesting. First, patients previously belonging to Hospital $\mathrm{P}$ and subsequently belonging to Hospital D have on average 2.8 days shorter LOS. Second, patients previously belonging to Hospital D who subsequently became the responsibility of Hospital P have on average 1.5 days longer LOS.

The estimation results based on the sub-sample of patients for whom there exist readyto-be-discharged dates are striking. Commenting only on the key variables, patients living in municipalities that change hospital From $P$ to $D$ stay approximately 2.3 days shorter at hospital after their potential discharge date, while the From $D$ to $P$ group of patients stay close to 3 days longer. These findings indicate that punishment does not contribute to reducing bed-blocking compared with a scheme without fines, rather the opposite. Nor does punishment have any advantage in terms of reducing overall LOS as previously shown. In regard to the analysis presented in Section 3, these findings suggest strong motivation crowding effects of monetary punishment. It is also interesting to notice that the effects are reasonably symmetric: LOS increases when monetary punishment is introduced and decreases when the incentive scheme is removed. ${ }^{14}$

\section{Discussion and concluding remarks}

One could argue that the reported results are not indications of differences in bed-blocking per se, but rather reflect differences in treatment techniques between Hospital P and Hospital D not accounted for in our analysis. We believe our results tell a different story, though. Most importantly, for a sub-sample of patients we observe hospital length of stay above the ready-fordischarge date. This length of stay should not be affected by treatment techniques, and using this measure as the dependent variable in the analysis only strengthen our results. Further, if different treatment techniques explain differences in LOS, we would expect different LOS for patients of all ages. As can be seen in Table 6 , this is not the case ${ }^{15}$. Here we estimate the same econometric model as above, but focus on different age groups of patients. Notice that there are

\footnotetext{
${ }^{14}$ This contrasts with the results of the aforementioned study by Gneezy and Rustichini (2000), where a removal of explicit monetary incentives did not have the oppositie effects of introducing the incentives in the first place.

${ }^{15}$ Because few young patients are transferred from hospital to a long-term care institution, we use all patients discharged from the two hospitals (the same sample as in Table 1) in these estimations.
} 
no significant differences in LOS between the two hospitals for patients younger than 40 years of age who change hospitals. Neither do we find a significant change in LOS for patients between 40 and 67 who move from Hospital D to Hospital P. In our opinion, the reason behind these results is that patients younger than 67 years of age are less likely to be in need of long-term care, at least at an institution. They recover more easily compared to older patients and they are more likely to have close family to take care of them if need be. We believe these results are strong indicators of the importance of how the interaction between hospitals and municipalities are organized. Henceforth, the estimation results for patients 67 years and over are quite robust in the sense that they are less likely to be attributed to differences in treatment practice as to differences in the way the two hospitals deal with bed-blocking.

We explain our findings by appealing to a motivation crowding story, where explicit monetary incentives crowd out intrinsic motivation of the agents that are subject to this type of regulation. At this point, in order to give this story some more weight, we would like to revisit a main result from our theoretical model in Section 3. Given that we have an interior solution with bed-blocking (which we do observe in reality), we saw that an a priori ambiguous effect of introducing monetary incentives relied on the condition that the marginal cost of hospital stay is higher than the daily fine. In our experiment, the daily penalty rate is 1.600 NOK $(2.000$ NOK in Oslo), which is well below the estimated average daily operation cost of 7-8.000 NOK in Norwegian hospitals (see Footnote 2). This suggests that the relevant conditions for plausibly explaining the results by motivation crowding are present in our experiment. This is also in line with a general prediction from the motivation crowding literature: relatively small amounts of extrinsic motivation are more likely to have negative effects on observed pro-social behaviour, since the motivation crowding effect in this case is more likely to dominate the relative price effect. $^{16}$

The main argument against the conclusion that monetary incentives are inferior compared to dialogue is of course that the design of the fining scheme is sub-optimal: the scheme does not provide a sufficient change in relative prices. If the daily bed-blocking fine is relatively large compared to marginal cost, the patients' home municipalities would have strong incentives to

\footnotetext{
${ }^{16}$ See, e.g., Meier (2006) for a further discussion of this point..
} 
reduce LOS for the group of patients we are studying. As obvious as that solution may sound, in practice it might be hard to implement. It would mean that the regulator is able to determine the optimal fine for each municipality in the country and be able to update these fines depending on changes in cost and capacity. The dialogue option, on the other hand, relies on decentralized decision making and there is no need for the regulator to collect cost information at all.

In a broader sense, our finding may also give support to the claim that using mutual agreements as a way of stimulating interdependent agents 'to sort out their differences' are in some instances a better solution compared to regulatory schemes based on fines. On the other hand, the fining scheme represents a fall-back option and may function as a vehicle for the parties to engage in dialogue: without fines, no dialogue and without dialogue, no substantial changes in the interaction, which leads to sub-optimal solutions. But still, what we here have termed 'dialogue' seems to make it easier for the institutions to agree on basic goals attached to patients' well-being and the aim of reducing bed-blocking - both elements will tend to drive LOS downwards - compared with a regulatory scheme based on fines. This also relates to the theoretical discussion in Section 3, where we mentioned the possibility of crowding in of intrinsic motivation due to external interventions that are perceived to be supportive. Thus, the different outcomes of the 'dialogue' and 'punishment' regimes could possibly be attributed to a mixture of crowding in (dialogue) and crowding out (punishment) effects.

By way of conclusion, we also would like to stress that whether or not bed-blocking eventually could be reduced by imposing monetary fines that are sufficiently high is somewhat besides the point here. Our study is not about optimal regulation to reduce hospital bed-blocking; rather, we wanted to test whether or not explicit monetary incentives would crowd out pro-social motivation in this particular context. And our results strongly suggest that this is the case. Thus, our results support the view that monetary incentive schemes may have counter-productive effects and may not always be the best way to motivate economic agents, given that other options are on the table. 


\section{References}

[1] Barkema, H.G., 1995. Do job executives work harder when they are monitored? Kyklos, $48,19-42$.

[2] Bénabou, R., Tirole, J., 2003. Intrinsic and extrinsic motivation. Review of Economic Studies, 70, 489-520.

[3] Bénabou, R., Tirole, J., 2006. Incentives and prosocial behavior. American Economic Review, 96, 1652-1678.

[4] Deci, E.L., 1971. Effects of externally mediated rewards on intrinsic motivation. Journal of Personality and Social Psychology, 18, 105-115.

[5] Deci, E.L., 1972. Intrinsic motivation, extrinsic reinforcement and inequity. Journal of Personality and Social Psychology, 22, 113-120.

[6] Frey, B.S., 1993. Motivation as a limit to pricing. Journal of Economic Psychology, 14, 635-664.

[7] Frey, B.S., 1997. Not just for the money. An economic theory of personal motivation. Cheltenham, UK: Edward Elgar.

[8] Frey, B.S., Jegen, R., 2001. Motivation crowding theory. Journal of Economic Surveys, 15, $589-611$.

[9] Frey, B.S., Oberholzer-Gee, F., 1997. The cost of price incentives: an empirical analysis of motivation crowding-out. American Economic Review, 87, 746-755.

[10] Gneezy, U., Rustichini, A., 2000. A fine is a price. Journal of Legal Studies, 29, 1-18.

[11] Lai, C.-C., Yang, C.-Y., Chang, J.-J., 2003. Environmental regulations and social norms. International Tax and Public Finance, 10, 63-75.

[12] Lepper, M.R., Greene, D. (eds), 1978. The hidden cost of reward: New perspectives in psychology of human motivation. Hillsdale, NY: Erlbaum. 
[13] Meier, S., 2006. A survey of economic theories and field evidence on pro-social behavior. FRB Boston Working Papers Series, no. 06-6. 


\section{Appendix}

Table 1. Average hospital length of stay (LOS) at Hospital P and Hospital D over time, all patients.

\begin{tabular}{lcccccccc}
\hline & \multicolumn{2}{c}{2002} & \multicolumn{2}{c}{2003} & \multicolumn{2}{c}{2004} & \multicolumn{2}{c}{2005} \\
\hline & $\mathrm{P}$ & $\mathrm{D}$ & $\mathrm{P}$ & $\mathrm{D}$ & $\mathrm{P}$ & $\mathrm{D}$ & $\mathrm{P}$ & $\mathrm{D}$ \\
\hline Patients younger & 3.82 & 3.60 & 3.85 & 3.57 & 3.98 & 3.49 & 4.11 & 3.51 \\
than 40 & $(4.40)$ & $(5.30)$ & $(4.70)$ & $(5.17)$ & $(5.06)$ & $(5.40)$ & $(6.06)$ & $(5.83)$ \\
Patients between & 7.30 & 5.47 & 7.37 & 5.27 & 7.14 & 5.22 & 6.46 & 5.24 \\
40 and 66 & $(10.88)$ & $(7.93)$ & $(12.76)$ & $(7.90)$ & $(11.68)$ & $(7.32)$ & $(10.48)$ & $(8.29)$ \\
Patients older & 9.63 & 6.64 & 9.16 & 6.51 & 9.31 & 6.68 & 8.75 & 6.89 \\
than 66 & $(11.77)$ & $(7.10)$ & $(10.99)$ & $(7.32)$ & $(12.10)$ & $(7.04)$ & $(10.76)$ & $(7.57)$ \\
\hline
\end{tabular}

Table 2. Number of patients between catchments areas and hospitals over time.

\begin{tabular}{lcccccccc}
\hline & \multicolumn{2}{c}{2002} & \multicolumn{2}{c}{2003} & \multicolumn{2}{c}{2004} & \multicolumn{2}{c}{2005} \\
\hline & $\mathrm{P}$ & $\mathrm{D}$ & $\mathrm{P}$ & $\mathrm{D}$ & $\mathrm{P}$ & $\mathrm{D}$ & $\mathrm{P}$ & $\mathrm{D}$ \\
\hline $\begin{array}{l}\text { Original catchments } \\
\text { area Hospital P }\end{array}$ & 1595 & 11 & 1730 & 22 & 1329 & 307 & 1039 & 471 \\
$\begin{array}{l}\text { Original catchments } \\
\text { area Hospital D }\end{array}$ & 7 & 1608 & 3 & 1745 & 291 & 1483 & 440 & 1339 \\
\hline
\end{tabular}

Table 3. Descriptive statistics, patients discharged to an institution.

\begin{tabular}{lcccc}
\hline & \multicolumn{2}{c}{$\begin{array}{c}\text { Original catchments area } \\
\text { Hospital P }\end{array}$} & \multicolumn{2}{c}{$\begin{array}{c}\text { Original catchments area } \\
\text { Hospital D }\end{array}$} \\
\hline & $\mathrm{P}-\mathrm{D}$ & $\mathrm{P}$ & $\mathrm{D}-\mathrm{P}$ & $\mathrm{D}$ \\
\hline Length of stay & $9.13(7.99)$ & $12.75(14.38)$ & $8.68(10.83)$ & $8.71(8.49)$ \\
Age & $81.78(7.06)$ & $82.78(6.98)$ & $81.03(6.83)$ & $81.14(6.98)$ \\
Male & $0.35(0.48)$ & $0.34(0.48)$ & $0.39(0.49)$ & $0.40(0.49)$ \\
DRG weight & $1.58(1.33)$ & $1.51(1.33)$ & $1.45(1.04)$ & $1.56(1.46)$ \\
Number co-morbidities & $3.04(1.74)$ & $3.57(1.95)$ & $3.47(1.88)$ & $2.95(1.70)$ \\
Malignant neoplasms & $0.06(0.23)$ & $0.07(0.26)$ & $0.04(0.19)$ & $0.09(0.29)$ \\
Diseases in the circulatory & $0.28(0.45)$ & $0.23(0.42)$ & $0.28(0.45)$ & $0.29(0.45)$ \\
system & & & & \\
Diseases in the respiratory & $0.12(0.32)$ & $0.09(0.28)$ & $0.13(0.34)$ & $0.10(0.29)$ \\
system & & & & \\
Home to institution & $0.95(0.43)$ & $0.90(0.30)$ & $0.91(0.29)$ & $0.91(0.29)$ \\
Gross expenses health care & 94.11 & 90.63 & 72.38 & 70.91 \\
Number of observations & 772 & 5732 & 719 & 6197 \\
\hline
\end{tabular}

Table 4. Average hospital length of stay (LOS) for patients in Hospital P' catchments area

\begin{tabular}{lcccc}
\hline & 2002 & 2003 & 2004 & 2005 \\
\hline Municipalities changing catchments & 6.89 & 6.64 & 7.77 & 9.25 \\
area (D - P) & $(6.53)$ & $(7.50)$ & $(8.71)$ & $(11.56)$ \\
Municipalities not changing & 11.37 & 10.63 & 11.14 & 10.34 \\
catchments area (D) & $(12.23)$ & $(11.79)$ & $(12.65)$ & $(10.95)$ \\
\hline
\end{tabular}


Table 5. Fixed effect analysis of hospital length of stay (LOS) for patients older than 67, robust standard errors

\begin{tabular}{|c|c|c|}
\hline & Length of stay (LOS) & $\begin{array}{l}\text { LOS above the "ready for } \\
\text { discharge" date }\end{array}$ \\
\hline Age & $-0.1542^{* * *}(0.0139)$ & $-0.0125(0.0128)$ \\
\hline Male & $0.3329^{*}(0.2037)$ & $0.3060^{*}(0.1777)$ \\
\hline DRG weight & $1.5919^{* * *}(0.1430)$ & $0.0054(0.0583)$ \\
\hline Number co-morbidities & $1.8429^{* * *}(0.0667)$ & $0.1357^{* * * *}(0.0448)$ \\
\hline Malignant neoplasms & $4.1818^{* * *}(0.1563)$ & $0.8491^{* * *}(0.2993)$ \\
\hline Diseases circulatory system & $1.9216^{* * *}(0.2374)$ & $0.3446^{*}(0.2046)$ \\
\hline Diseases respiratory system & $1.2937^{* * *}(0.2875)$ & $-0.2710(0.2914)$ \\
\hline Home to institution & $1.8006^{* * *}(0.2964)$ & $-0.4782(0.3681)$ \\
\hline From $\mathrm{P}$ to $\mathrm{D}$ & $-2.8044^{* * * *}(0.3430)$ & $-2.2365^{* * *}(0.2694)$ \\
\hline From $\mathrm{D}$ to $\mathrm{P}$ & $1.5310^{* * *}(0.4469)$ & $2.9940^{* * *}(0.6534)$ \\
\hline Gross expenses health care & $-0.1126^{* * * *}(0.0442)$ & $-0.1313^{*}(0.0709)$ \\
\hline 2003 & $-1.0457^{* * *}(0.2946)$ & $0.2159(0.4828)$ \\
\hline 2004 & $-0.0873(0.4194)$ & $-0.7515(0.6174)$ \\
\hline 2005 & $-0.4603(0.4144)$ & $-0.7318(0.6119)$ \\
\hline Constant & $21.5400^{* * *}(3.5913)$ & $18.4073^{* * *}(5.6329)$ \\
\hline $\mathrm{R}^{2}$ & 0.17 & 0.08 \\
\hline Number of municipalities & 16 & 16 \\
\hline Number of observations & 13420 & 2666 \\
\hline
\end{tabular}


Table 6. Fixed effect analysis of hospital length of stay for patients in different age groups, robust standard errors.

\begin{tabular}{|c|c|c|c|c|}
\hline & Younger than 40 & $\begin{array}{c}\text { Between } 40 \text { and } \\
67\end{array}$ & $\begin{array}{c}\text { Between } 67 \text { and } \\
80\end{array}$ & Older than 80 \\
\hline Age & $\begin{array}{l}-0.0090^{* * *} \\
(0.0027)\end{array}$ & $\begin{array}{l}0.0222^{* * *} \\
(0.0059)\end{array}$ & $\begin{array}{l}-0.0307^{*} \\
(0.0162)\end{array}$ & $\begin{array}{l}-0.0823^{* * *} \\
(0.0126)\end{array}$ \\
\hline Male & $\begin{array}{l}0.0227 \\
(0.0666)\end{array}$ & $\begin{array}{l}0.0516 \\
(0.0907)\end{array}$ & $\begin{array}{l}0.1887 \\
(0.1157)\end{array}$ & $\begin{array}{l}0.0354 \\
(0.1092)\end{array}$ \\
\hline DRG weight & $\begin{array}{l}2.8513^{* * *} \\
(0.2020)\end{array}$ & $\begin{array}{l}2.2246^{* * *} \\
(0.1208)\end{array}$ & $\begin{array}{l}2.1231^{* * *} \\
(0.1193)\end{array}$ & $\begin{array}{l}1.7594^{* * *} \\
(0.1180)\end{array}$ \\
\hline $\begin{array}{l}\text { Number of co- } \\
\text { morbidities }\end{array}$ & $\begin{array}{l}0.7053^{* * *} \\
(0.0387)\end{array}$ & $\begin{array}{l}1.6648^{* * *} \\
(0.0557)\end{array}$ & $\begin{array}{l}1.5661^{* * *} \\
(0.0532)\end{array}$ & $\begin{array}{l}1.3650^{* * *} \\
(0.0435)\end{array}$ \\
\hline Malignant neoplasms & $\begin{array}{l}1.1928^{* * *} \\
(0.3530)\end{array}$ & $\begin{array}{l}1.7173^{* * *} \\
(0.2231)\end{array}$ & $\begin{array}{l}2.1790^{* * *} \\
(0.2131)\end{array}$ & $\begin{array}{l}2.3476^{* * *} \\
(0.2266)\end{array}$ \\
\hline $\begin{array}{l}\text { Diseases circulatory } \\
\text { system }\end{array}$ & $\begin{array}{l}0.8120^{* * *} \\
(0.2458)\end{array}$ & $\begin{array}{l}-0.6228^{* * *} \\
(0.1260)\end{array}$ & $\begin{array}{l}-0.3884^{* * *} \\
(0.1367)\end{array}$ & $\begin{array}{l}0.5810^{* * *} \\
(0.1280)\end{array}$ \\
\hline $\begin{array}{l}\text { Diseases respiratory } \\
\text { system }\end{array}$ & $\begin{array}{l}-0.8198^{* * *} \\
(0.0964)\end{array}$ & $\begin{array}{l}0.1634 \\
(0.1817)\end{array}$ & $\begin{array}{l}0.0745 \\
(0.1620)\end{array}$ & $\begin{array}{l}0.8592^{* * *} \\
(0.1504)\end{array}$ \\
\hline Home to institution & $\begin{array}{l}0.4005 \\
(0.2558)\end{array}$ & $\begin{array}{l}2.2831^{* * *} \\
(0.2477)\end{array}$ & $\begin{array}{l}2.5521^{* * *} \\
(0.1966)\end{array}$ & $\begin{array}{l}1.8445^{* * *} \\
(0.1321)\end{array}$ \\
\hline From $P$ to $D$ & $\begin{array}{l}-0.0761 \\
(0.0849)\end{array}$ & $\begin{array}{l}-1.4216^{* * *} \\
(0.1814)\end{array}$ & $\begin{array}{l}-1.6312^{* * *} \\
(0.2461)\end{array}$ & $\begin{array}{l}-2.1120^{* * *} \\
(0.1809)\end{array}$ \\
\hline From $\mathrm{D}$ to $\mathrm{P}$ & $\begin{array}{l}-0.1227 \\
(0.1583)\end{array}$ & $\begin{array}{l}0.0834 \\
(0.2313)\end{array}$ & $\begin{array}{l}1.0040^{* * *} \\
(0.3156)\end{array}$ & $\begin{array}{l}1.4655^{* * *} \\
(0.2976)\end{array}$ \\
\hline $\begin{array}{l}\text { Gross expenses health } \\
\text { care }\end{array}$ & $\begin{array}{l}-0.0044 \\
(0.0120)\end{array}$ & $\begin{array}{l}0.0159 \\
(0.0234)\end{array}$ & $\begin{array}{l}-0.0165 \\
(0.0309)\end{array}$ & $\begin{array}{l}-0.0435^{*} \\
(0.0252)\end{array}$ \\
\hline 2003 & $\begin{array}{l}-0.1740^{* *} \\
(0.0753)\end{array}$ & $\begin{array}{l}-0.5335^{* * *} \\
(0.1546)\end{array}$ & $\begin{array}{l}-0.5723^{* * *} \\
(0.1938)\end{array}$ & $\begin{array}{l}-0.7978^{* * *} \\
(0.1637)\end{array}$ \\
\hline 2004 & $\begin{array}{l}-0.1558 \\
(0.1090)\end{array}$ & $\begin{array}{l}-0.7310^{* * *} \\
(0.2234)\end{array}$ & $\begin{array}{l}-0.5567^{* * *} \\
(0.2895)\end{array}$ & $\begin{array}{l}-0.3650 \\
(0.2404)\end{array}$ \\
\hline 2005 & $\begin{array}{l}-0.1498^{* * *} \\
(0.0718)\end{array}$ & $\begin{array}{l}-0.9402^{* * *} \\
(0.2240)\end{array}$ & $\begin{array}{l}-0.6745^{* * *} \\
(0.2876)\end{array}$ & $\begin{array}{l}-0.4344^{*} \\
(0.2383)\end{array}$ \\
\hline Constant & $\begin{array}{l}1.1143 \\
(0.1114)\end{array}$ & $\begin{array}{l}-1.1923 \\
(1.7595)\end{array}$ & $\begin{array}{l}4.6843^{*} \\
(2.5306)\end{array}$ & $\begin{array}{l}11.7158^{* * *} \\
(2.2327)\end{array}$ \\
\hline $\mathrm{R}^{2}$ & 0.25 & 0.26 & 0.21 & 0.17 \\
\hline $\begin{array}{l}\text { Number of } \\
\text { municipalities }\end{array}$ & 16 & 16 & 16 & 16 \\
\hline Number of observations & 41262 & 33601 & 24324 & 24051 \\
\hline
\end{tabular}


Table 7. Descriptive statistics, subsample registered with a "ready for discharge" date

\begin{tabular}{|c|c|c|c|c|}
\hline & \multicolumn{2}{|c|}{$\begin{array}{c}\text { Original catchments area } \\
\text { Hospital P }\end{array}$} & \multicolumn{2}{|c|}{$\begin{array}{c}\text { Original catchments area } \\
\text { Hospital D }\end{array}$} \\
\hline & $P-D$ & $\mathrm{P}$ & $\mathrm{D}-\mathrm{P}$ & $\mathrm{D}$ \\
\hline Length of stay (LOS) & $12.61(9.13)$ & $20.12(15.63)$ & $18.60(15.96)$ & $13.61(9.40)$ \\
\hline $\begin{array}{l}\text { LOS > "ready for discharge" } \\
\text { date }\end{array}$ & $4.08(3.58)$ & $7.19(3.69)$ & $6.07(4.44)$ & $5.37(5.02)$ \\
\hline Age & $82.27(6.62)$ & $83.51(6.53)$ & $82.58(6.48)$ & $81.66(6.65)$ \\
\hline Male & $0.31(0.46)$ & $0.33(0.47)$ & $0.36(0.48)$ & $0.35(0.48)$ \\
\hline DRG weight & $1.68(0.82)$ & $1.50(1.48)$ & $1.62(0.75)$ & $1.80(1.86)$ \\
\hline Number co-morbidities & $3.28(1.72)$ & $4.08(1.98)$ & $4.26(1.81)$ & $3.31(1.77)$ \\
\hline Malignant neoplasms & $0.05(0.23)$ & $0.11(0.31)$ & $0.06(0.23)$ & $0.09(0.29)$ \\
\hline $\begin{array}{l}\text { Diseases in the circulatory } \\
\text { system }\end{array}$ & $0.27(0.44)$ & $0.20(0.40)$ & $0.30(0.46)$ & $0.25(0.43)$ \\
\hline $\begin{array}{l}\text { Diseases in the respiratory } \\
\text { system }\end{array}$ & $0.11(0.31)$ & $0.09(0.28)$ & $0.13(0.34)$ & $0.07(0.29)$ \\
\hline Home to institution & $0.99(0.12)$ & $0.94(0.23)$ & $0.96(0.21)$ & $0.93(0.26)$ \\
\hline Gross expenses health care & 94.11 & 90.63 & 72.38 & 70.91 \\
\hline Number of observations & 221 & 1374 & 89 & 982 \\
\hline
\end{tabular}

